\title{
DESIGN, DEVELOPMENT, AND CHARACTERIZATION OF TOPICAL GEL CONTAINING ITRACONAZOLE - ANTIFUNGAL AGENT
}

\author{
PAVITHRA K, JEGANATH S*, AZEEM IQBAL \\ Department of Pharmaceutics, School of Pharmaceutical Sciences, Vels Institute of Science, Technology and Advanced Studies, Pallavaram, \\ Chennai, Tamil Nadu, India. Email: jeganaths@gmail.com
}

Received: 10 October 2018, Revised and Accepted: 11 December 2018

\section{ABSTRACT}

Objective: The main purpose of this study was to develop a topical delivery of itraconazole to reduce the dose of the drug, to improve patient compliance, and to avoid the side effects. Itraconazole is a triazole derivative to treat antifungal and antiprotozoal infections.

Methods: Topical gel formulations of itraconazole were prepared using Carbopol 940 as a gelling agent with different concentrations. Four different formulations were prepared and evaluated with respect to color, spreadability, viscosity measurement, determination of $\mathrm{pH}$, drug content, in vitro drug release studies, zeta potential studies, and stability studies. Compatibility study was carried out by Fourier-transform infrared (FT-IR) spectral analysis.

Results: FT-IR study revealed that there were no significant interaction between the drug and polymers. All the prepared formulations show acceptable physical properties. The drug content and percentage yield were higher for F1 formulation among all formulation F1 shows better drug release. Stability study of best formulation shows that there was no difference in drug content and in vitro drug release studies.

Conclusion: From the above observation results that this formulation may be more encouraging topical substitute for the healing of fungal infections in the skin.

Keywords: Itraconazole, Carbopol 940, Zeta potential, Stability study.

(C) 2018 The Authors. Published by Innovare Academic Sciences Pvt Ltd. This is an open access article under the CC BY license (http://creativecommons. org/licenses/by/4. 0/) DOI: http://dx.doi.org/10.22159/ajpcr.2018.v11s4.31725

\section{INTRODUCTION}

Topical drug administration is one of the localized drug delivery system given through ophthalmic, vaginal, rectal, and skin as topical routes. Topical route of drug delivery system has attained popularity as it avoids first-pass effects, gastrointestinal irritation, and metabolic degradation associated with oral administration. Due to the first past effect only $25-/ 45 \%$ of the orally administered dose reaches the blood circulation. In order to bypass these disadvantages the gel formulations have been proposed as topical application [1]. Topical gel formulations give an appropriate distribution system as they are less greasy and straightforward to get rid of the skin.

Nowadays, the dermatological complication majorly caused due to fungal infection. The medical practitioner has mentioned treatment through following dosage formulations such as solid, liquid, and semi-solid [2]. Transparent gels are broadly used topical formulations in both cosmetics and pharmaceuticals.

The drug is applied to the mucous membrane or skin that may enhance the skin simple operate and alters its action. Those products are called topical or dermatological products.

We must know the skin anatomy, physiology, and physicochemical properties and it is used for the percutaneous absorption [3]. Skin is made up of three layers: Dermis, epidemi, and hypodermis (subcutaneous layer). The width of epidermis is 0.1-1.5 $\mathrm{mm}$ and it has five division: Stratum basale, stratum spinosum, stratum granulosum, stratum lucidum, and stratum corneum [4]. Epidermis secretes melanin from melanocytes. The squamous cell layer is the widest layer that moves irrefutable substances inside and outside of the body.

\section{MATERIALS AND METHODS}

\section{Materials}

Itraconazole was acquired from Sigma-Aldrich, Chennai, India. Carbopol was obtained from Sigma-Aldrich, Chennai, India. All Other Chemicals used were of the standard analytical grade.

\section{Method of preparation of topical gel containing itraconazole}

Topical gel formulations were prepared using various concentration of polymer Carbopol 940 is dispersed in cozy water with constant stirring by magnetic stirrer at a medium pace. Required amount of drug is dissolved with propylene glycol, and it was neutralized with triethanolamine of sufficient quantity in it with constant stirring [3]. Glycerin and propylparaben are added little by little with constant stirring until it forms a homogeneous gel. Gels are packed in a widemouthed glass jar, and it is covered with screw copped plastic lid after covering with aluminum foil $[5,6]$. Various preparations of itraconazole topical gel are shown in Table 1. They were kept in the dark and cool place.

Evaluation of physicochemical parameters of prepared itraconazole gel

\section{Drug-excipients compatibility studies}

Fourier transfer infrared spectrophotometer (FTIR)

The drug, polymer, and excipient interactions are studied using the FTIR method. In general, drug and excipients must be coinciding with each other which produce a stable, safe, and efficacious product. IR spectral analysis of pure drug and polymers was transported out [7]. Pure drug that gives peak and patterns were compared with the peaks and patterns with the combination of polymer and drug. 
Table 1: Formulation of itraconazole topical gel

\begin{tabular}{lllll}
\hline Ingredients & F1 & F2 & F3 & F4 \\
\hline Itraconazole & 1 & 1 & 1 & 1 \\
Carbopol 940 & 1 & 1.5 & 2 & 2.5 \\
Propylene glycol & 3 & 3 & 3 & 3 \\
Propylparaben & 0.01 & 0.01 & 0.01 & 0.01 \\
Glycerin & 10 & 10 & 10 & 10 \\
Triethanolamine & 4 & 4 & 4 & 4 \\
Water up to & 100 & 100 & 100 & 100 \\
\hline
\end{tabular}

\section{Zeta potential}

Zeta potential is the measurement of attraction or repulsion in between particles. Its measurement brings details about the dispersion mechanism which is used to measure electrostatic dispersion [8].

The zeta potential calculation is a important limitation across a various range of industries incorporates pharmaceuticals, brewing, medicine, ceramics, and water treatment. For colloidal stability, the repulsive forces between two particles should be ascendant [9]. Zeta potential is a useful index of magnitude for interaction between colloidal particles. In general, the colloidal systems stability is determined using measurements based on zeta potential.

\section{Visual properties}

A physical property of the gel formulations was determined by visual observation for their color, uniformity, transparency, and phase separation. The prepared gels show uniformity without clumps [10]

\section{Determination of $\mathbf{p H}$}

The digital $\mathrm{pH}$ meter is used to find out the $\mathrm{pH}$ value of a formulated topical gel. The values of prepared formulations are between the ranges of 4-8 that ignores the chance of skin irritation [11].

\section{Spread ability}

The assessment of spread capacity, two glass slides were taken, and the prepared gel was compressed in between the two glass slides to steady stability by applying weight and leaves it for $6 \mathrm{~min}$ [12]. The value of spreadability is gathered by determining the time taken for the two glass slides to get separated.

\section{Percentage yield}

The practical yield of each sample is determined by weighing the empty container and the container along with the gel formulation and subtraction of empty container with the container along with the gel [9].

\section{Uniformity of drug content}

The expression "uniformity of dosage unit" is explained as the substances degree of uniformity among dosage units. The content uniformity test depends on the assay of the active medicament. $100 \mathrm{mg}$ of the formulated gel is taken and dissolved in $100 \mathrm{ml}$ of phosphate buffer of $\mathrm{pH}$ 6.8. The above solution is allowed to stand for $30 \mathrm{~min}$ followed by gentle stirring to enhance the solubility of the drug [13]. Then, it is treated, and the absorbance of the solution was identified spectrophotometrically at $296 \mathrm{~nm}$ using phosphate buffer $\mathrm{pH} 6.8$ as blank.

\section{Grittiness}

The existence of particles in the formulations was determined microscopically [14], if there is no specific matter when observed under light microscope.

\section{Viscosity estimation}

Alteration in viscosity of the product displays adjustment instability and efficacy of the product. Uniformity of formulation lies on the ratio of the solid fraction to liquid fraction which constructs gel structure [15]. The viscosity of topical gels was acquired using Brook-
Field viscometer DE-V model using spindle no 61 and spindle speed of $50 \mathrm{rpm}$ at $37^{\circ} \mathrm{C}$.

\section{In vitro drug release}

Franz-diffusion cells equipment is used to study the in vitro drug release using various formulations [16]. The specific quantity of formulation was applied on the membrane positioned between the donor and receptor chambers with an available diffusion area. Fill the receptor chamber with phosphate buffer $\mathrm{pH} 6.8$ and is blended repeatedly with a tiny magnetic bead, the speed of $50 \mathrm{rpm}$ is continued at the temperature at $37^{\circ} \mathrm{C} \pm 2^{\circ} \mathrm{C}$. At different meantime, the samples were taken and then it is exchanged with the same volume of phosphate buffer $\mathrm{pH} 6.8$ to maintain the volume of dissolution medium [11]. In all cases, sink conditions are seen. The obtained samples were analyzed spectrophotometrically at $296 \mathrm{~nm}$.

\section{Stability study}

The concentration of an active ingredient of all formulation may fall with upraise in the temperature and time. This assists in drop in the potency of the product. Stability study in various temperatures ought to be dispensed to anticipate the formulation stability.

Stability studies are strenuous at regulating the outcome of aging and storage under divers circumstance on the formulated gel. Stability studies take place to detect whether any chemical breakdown of itraconazole formulations take place or not [17]. The chief formulation was kept at $30 \pm 2{ }^{\circ} \mathrm{C}$ and $40 \pm 2^{\circ} \mathrm{C}$ at RH $65 \pm 5$ and $75 \pm 5$ RH for 2 months in a glass vial. After 1 or 2 months, the samples were repeatedly tested for the drug content and in vitro release studies.

\section{RESULTS AND DISCUSSION}

\section{Drug-excipients compatibility studies}

The IR studies of clear Itraconazole formulation comprises greater proportion of the polymers that are conducted to know about the bond between the used polymers and the drug. The outcome is represented in Figs. 1-3.

The IR spectrum of pure itraconazole and itraconazole gel formulations that posses greater proportion of polymer that gives comparable basic patterns and peaks. Outcome status that no notable drug and polymer interactions.

\section{Visual inspection}

Visual determination is done to examine the syneresis and color of the developed formulation. The preparations must be logical and translucent. Eventually, the formulated gel shows better homogeneity without any lumps and syneresis.

\section{Determination of $\mathrm{pH}$}

The $\mathrm{pH}$ value of all developed gel was in the range of 6.6-7.1. This is sufficient for appealing to skin and avoid the chances of irritation. The outcome is available in Table 2 .

\section{Spreadability}

The study has a few major elements that show the gel character that emerges out from the tube. The values of spreadability are given in Table 2. Spreadability test is carried for all the formulations. Spreadability of the gel formulation drops with respect to increase in the polymer concentration.

\section{Determination of drug content}

The drug content of the formulated gel was estimated. Results are represented in Table 2. The drug content manifests that the drug was distributed equally throughout the gel.

\section{Percentage yield and viscosity}

Percentage yield of a topical gel consisting of itraconazole was in the range of 96.89-98.87\%. The values are stated in Table 3. This was identified that the percentage yield of $\mathrm{F} 2$ formulation showed an increase 


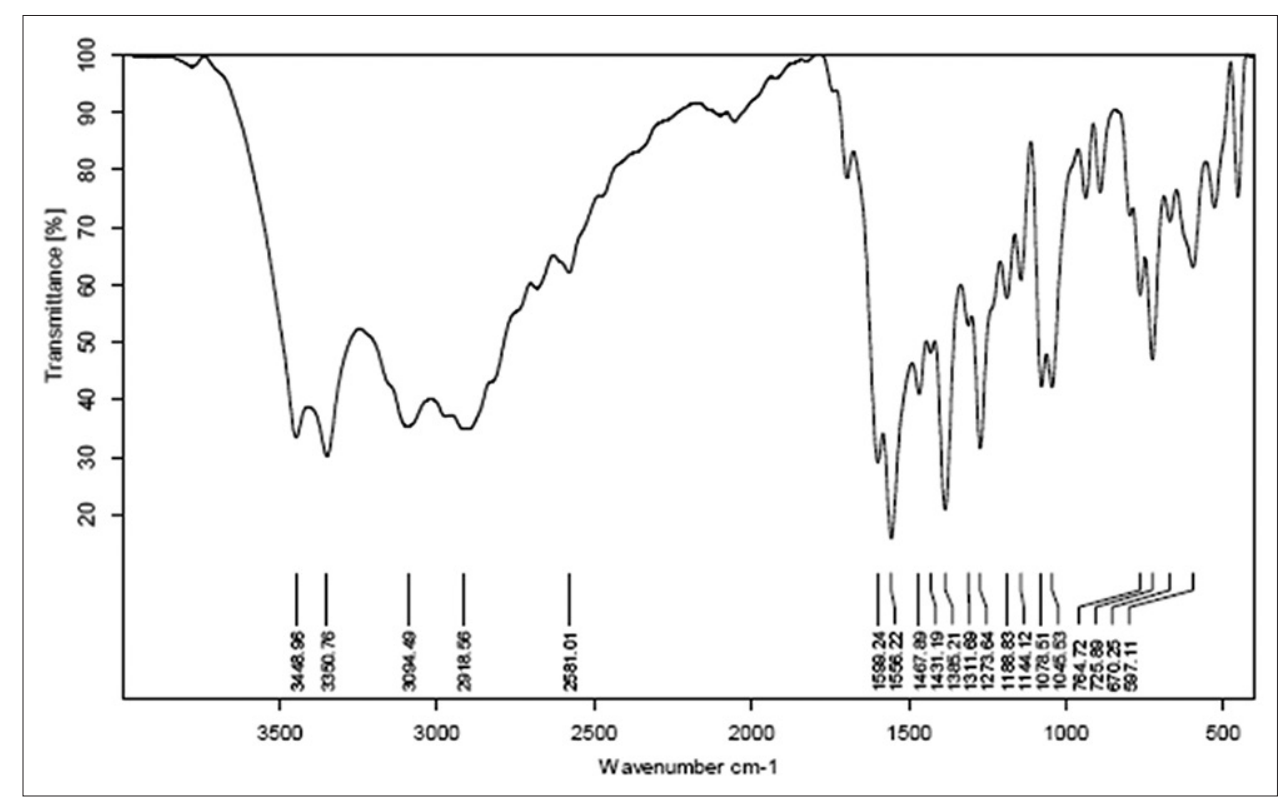

Fig. 1: Fourier-transform infrared spectrum of itraconazole

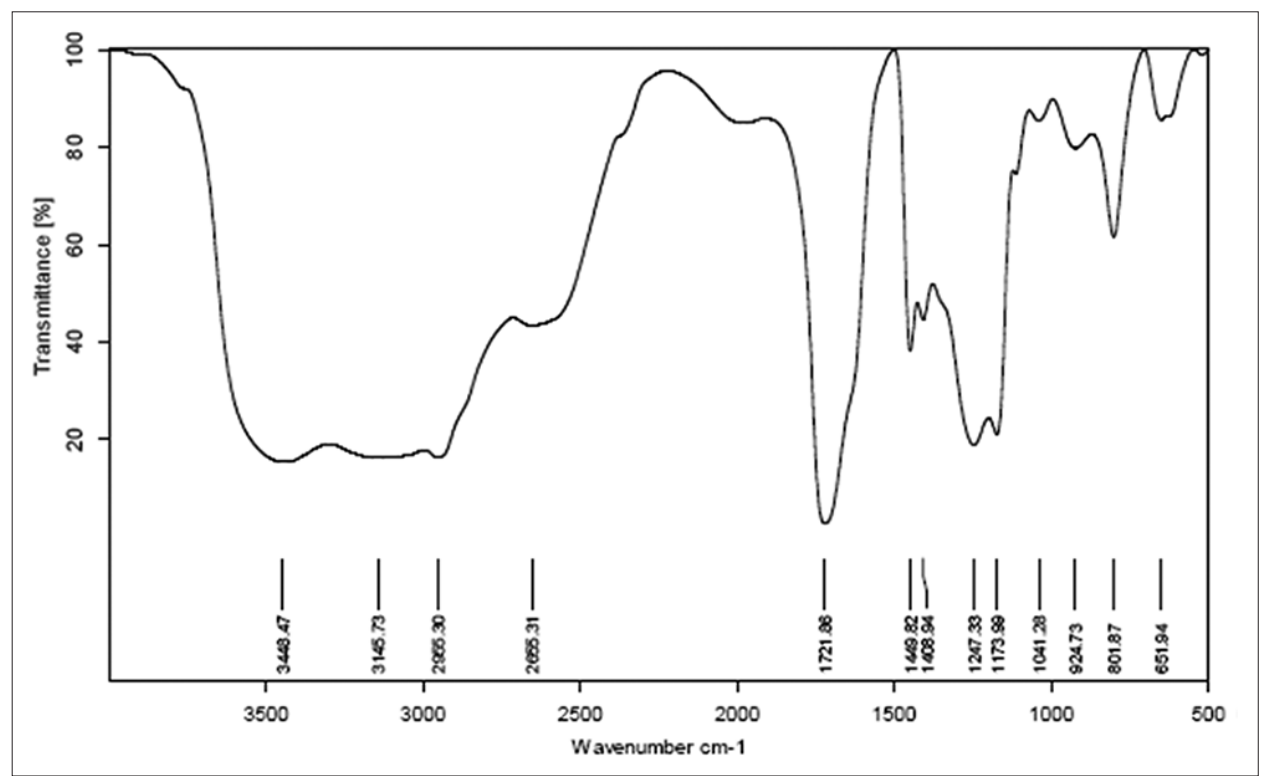

Fig. 2: Fourier-transform infrared spectrum of Carbopol 940

Table 2: pH, spreadability, and drug content of formulations (F1-F4)

\begin{tabular}{llll}
\hline Formulation code & pH & Spreadability $\left(\mathbf{g} . \mathrm{cm}^{2}\right)$ & Drug content \% \\
\hline F1 & 7.1 & 10.75 & $98.67 \pm 0.021$ \\
F2 & 6.8 & 11.08 & $96.32 \pm 0.012$ \\
F3 & 6.9 & 11.75 & $97.43 \pm 0.024$ \\
F4 & 6.6 & 10.25 & $96.01 \pm 0.018$ \\
\hline
\end{tabular}

Table 3: Percentage yield and viscosity of different formulations (F1-F4)

\begin{tabular}{lll}
\hline Formulation code & Percentage yield \% & Viscosity (centipoises) \\
\hline F1 & 97.39 & 2431 \\
F2 & 98.87 & 3741 \\
F3 & 96.89 & 4321 \\
F4 & 98.01 & 5102 \\
\hline
\end{tabular}

Table 4: Zeta potential (standard)

\begin{tabular}{lll}
\hline Peak no. & Zeta potential & $\begin{array}{l}\text { Electrophoretic } \\
\text { mobility }\end{array}$ \\
\hline 1 & $14.4 \mathrm{mV}$ & $-0.000016 \mathrm{~cm}^{2} / \mathrm{Vs}$ \\
2 & $0.00 \mathrm{mV}$ & $0.00 \mathrm{~cm}^{2} / \mathrm{Vs}$ \\
3 & $0.00 \mathrm{mV}$ & $0.00 \mathrm{~cm}^{2} / \mathrm{Vs}$ \\
\hline Zeta potential $(\mathrm{mean}):-2.0 \mathrm{mV}$. Electrophoretic mobility \\
mean: $-0.000016 \mathrm{~cm}^{2} / \mathrm{Vs}$
\end{tabular}

Table 5: Zeta potential (sample)

\begin{tabular}{lll}
\hline Peak no. & Zeta potential & Electrophoretic mobility \\
\hline 1 & $14.4 \mathrm{mV}$ & $-0.000029 \mathrm{~cm}^{2} / \mathrm{Vs}$ \\
2 & $0.00 \mathrm{mV}$ & $0.00 \mathrm{~cm}^{2} / \mathrm{Vs}$ \\
3 & $0.00 \mathrm{mV}$ & $0.00 \mathrm{~cm}^{2} / \mathrm{Vs}$ \\
\hline Zeta potential (mean): $-14.4 \mathrm{mV}$. Electrophoretic mobility \\
mean: $-0.000029 \mathrm{~cm}^{2} / \mathrm{vs}$
\end{tabular}




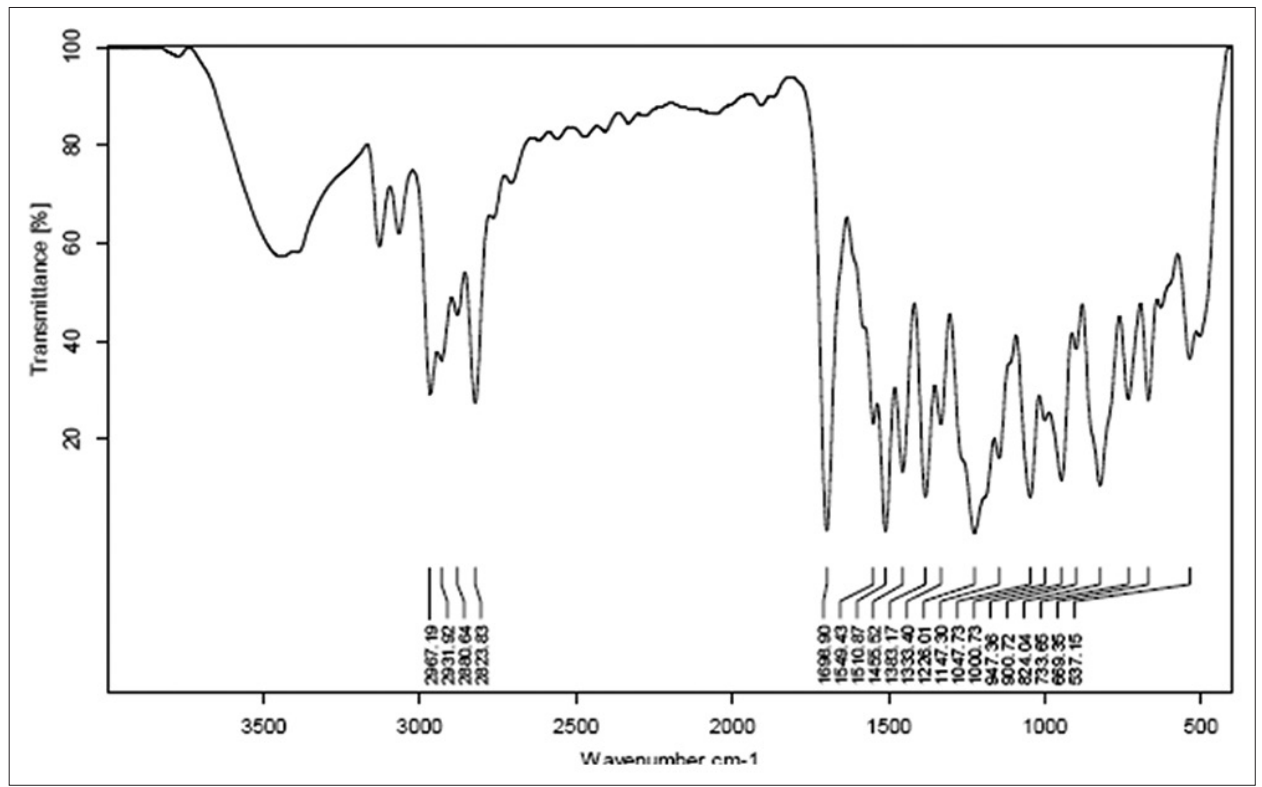

Fig. 3: Fourier-transform infrared spectrum of drug + polymer

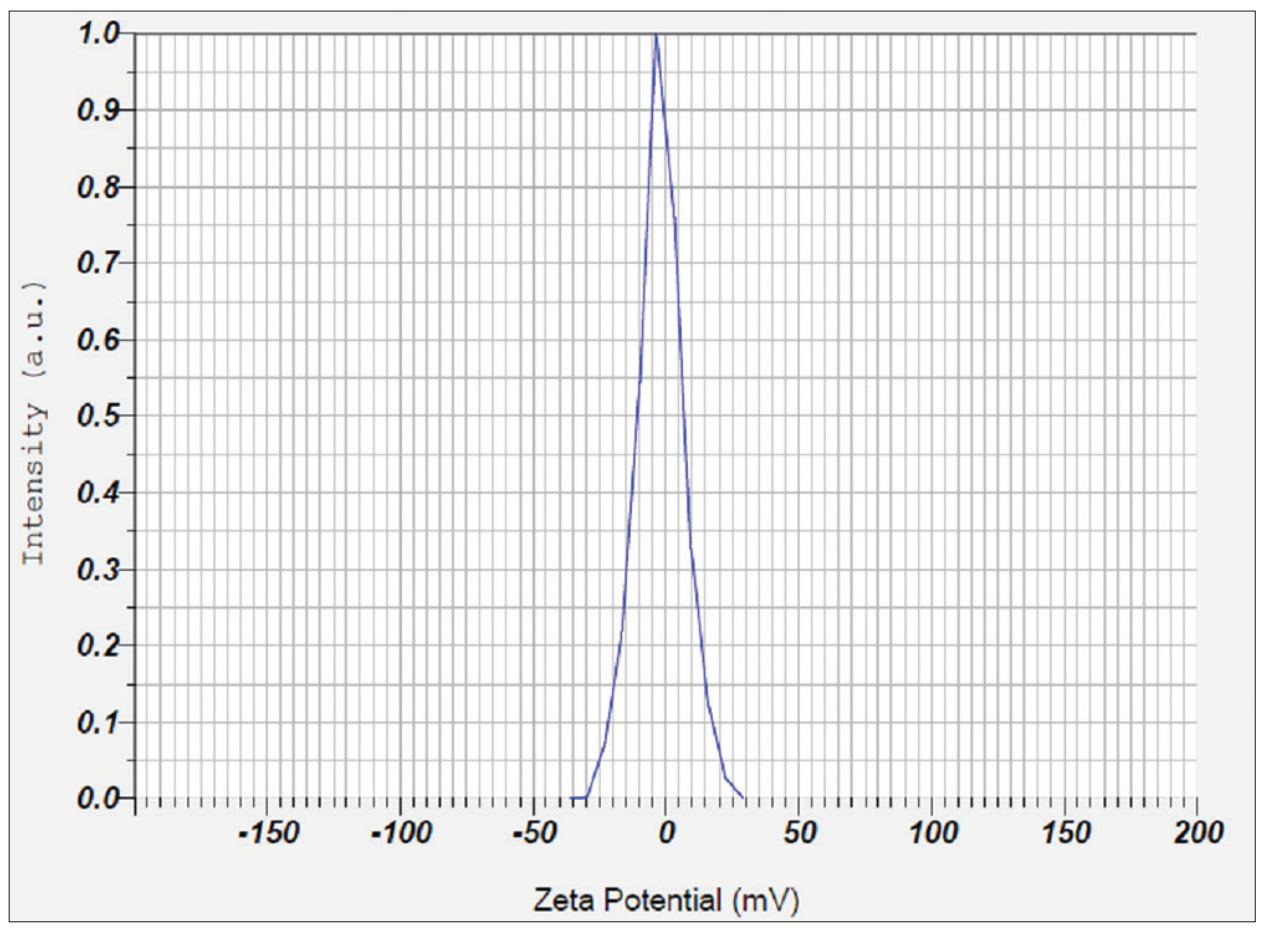

Fig. 4: Measurement of zeta potential (standard)

Table 6: Comparative dissolution study of different formulations with various ratios of polymers

\begin{tabular}{llllll}
\hline \multirow{2}{*}{ S.No } & Time (min) & \multicolumn{4}{l}{ \% Drug release } \\
\cline { 3 - 6 } & & F1 & F2 & F3 & F4 \\
\hline 1 & 30 & 10.96 & 9.54 & 11.45 & 8.90 \\
2 & 60 & 25.56 & 21.07 & 22.79 & 20.06 \\
3 & 90 & 38.12 & 33.91 & 35.41 & 34.55 \\
4 & 120 & 52.23 & 45.44 & 47.33 & 48.23 \\
5 & 150 & 64.45 & 59.71 & 57.21 & 60.10 \\
6 & 180 & 75.07 & 72.23 & 70.39 & 71.86 \\
7 & 210 & 85.34 & 82.86 & 80.05 & 83.24 \\
8 & 240 & 90.33 & 89.96 & 88.80 & 91.49 \\
9 & 270 & 96.12 & 98.72 & 99.01 & 99.34 \\
\hline
\end{tabular}

in percentage yield than the other preparation. In general, consistency of formulation depends on the ratio of the solid fraction to liquid fraction which produces gel structure. The data are presented in Table 3.

\section{Zeta potential for standard (water)}

A zeta potential value of standard (water) is stated in Table 4, and the crown depiction of the data is shown in Fig. 4.

\section{Zeta potential for sample}

Zeta potential values of the formulation sample are expressed in Table 5, and the crown depiction of the data is shown in Fig. 5.

In vitro drug release

The drug release profile of itraconazole topical gel formulations was accomplished by diffusion cell. As an outcome of the in vitro release 
Table 7: Stability study of F1 optimized formulation

\begin{tabular}{|c|c|c|c|c|c|c|}
\hline \multirow[t]{3}{*}{ S.No } & \multirow[t]{3}{*}{ Time (mins) } & \multirow[t]{3}{*}{0 Days } & \multicolumn{4}{|c|}{ Percentage \% drug release } \\
\hline & & & \multicolumn{2}{|l|}{30 days } & \multicolumn{2}{|l|}{60 days } \\
\hline & & & $30 \pm 2 C$ & $40 \pm 2 C$ & $30 \pm 2 C$ & $40 \pm 2 C$ \\
\hline 1 & 30 & 10.96 & $10.95 \pm 0.12$ & $10.95 \pm 0.01$ & $10.94 \pm 0.14$ & $10.94 \pm 0.12$ \\
\hline 2 & 60 & 25.56 & $25.54 \pm 0.11$ & $25.51 \pm 0.81$ & $25.54 \pm 0.41$ & $24.96 \pm 0.19$ \\
\hline 3 & 90 & 38.12 & $38.0 \pm 0.94$ & $38.1 \pm 0.91$ & $37.9 \pm 0.81$ & $37.6 \pm 0.12$ \\
\hline 4 & 120 & 52.23 & $52.21 \pm 0.41$ & $52.19 \pm 0.13$ & $52.0 \pm 0.12$ & $51.96 \pm 0.21$ \\
\hline 6 & 180 & 75.07 & $75.0 \pm 1.06$ & $74.91 \pm 1.27$ & $74.71 \pm 1.52$ & $74.6 \pm 1.89$ \\
\hline 7 & 210 & 85.34 & $85.21 \pm 0.14$ & $85.2 \pm 0.09$ & $85.16 \pm 0.41$ & $85.12 \pm 1.2$ \\
\hline 8 & 240 & 90.33 & $90.32 \pm 0.132$ & $90.21 \pm 1.35$ & $90.19 \pm 1.89$ & $90.13 \pm 1.161$ \\
\hline 9 & 270 & 96.12 & $96.96 \pm 1.72$ & $94.69 \pm 1.47$ & $96.62 \pm 1.12$ & $95.59 \pm 1.37$ \\
\hline
\end{tabular}

Table 8: Drug content estimation after storing at different temperatures (F1)

\begin{tabular}{|c|c|c|c|c|c|}
\hline \multirow[t]{3}{*}{ S.No } & \multirow[t]{3}{*}{ Formulation } & \multicolumn{4}{|c|}{ Drug content } \\
\hline & & \multicolumn{2}{|l|}{$30 \pm 2 C$} & \multicolumn{2}{|l|}{$40 \pm 2 C$} \\
\hline & & 30 days & 60 days & 30 days & 60 days \\
\hline 1 & F1 & $98.01 \pm 0.01$ & $97.48 \pm 0.02$ & $98.39 \pm 0.01$ & $97.87 \pm 0.06$ \\
\hline
\end{tabular}

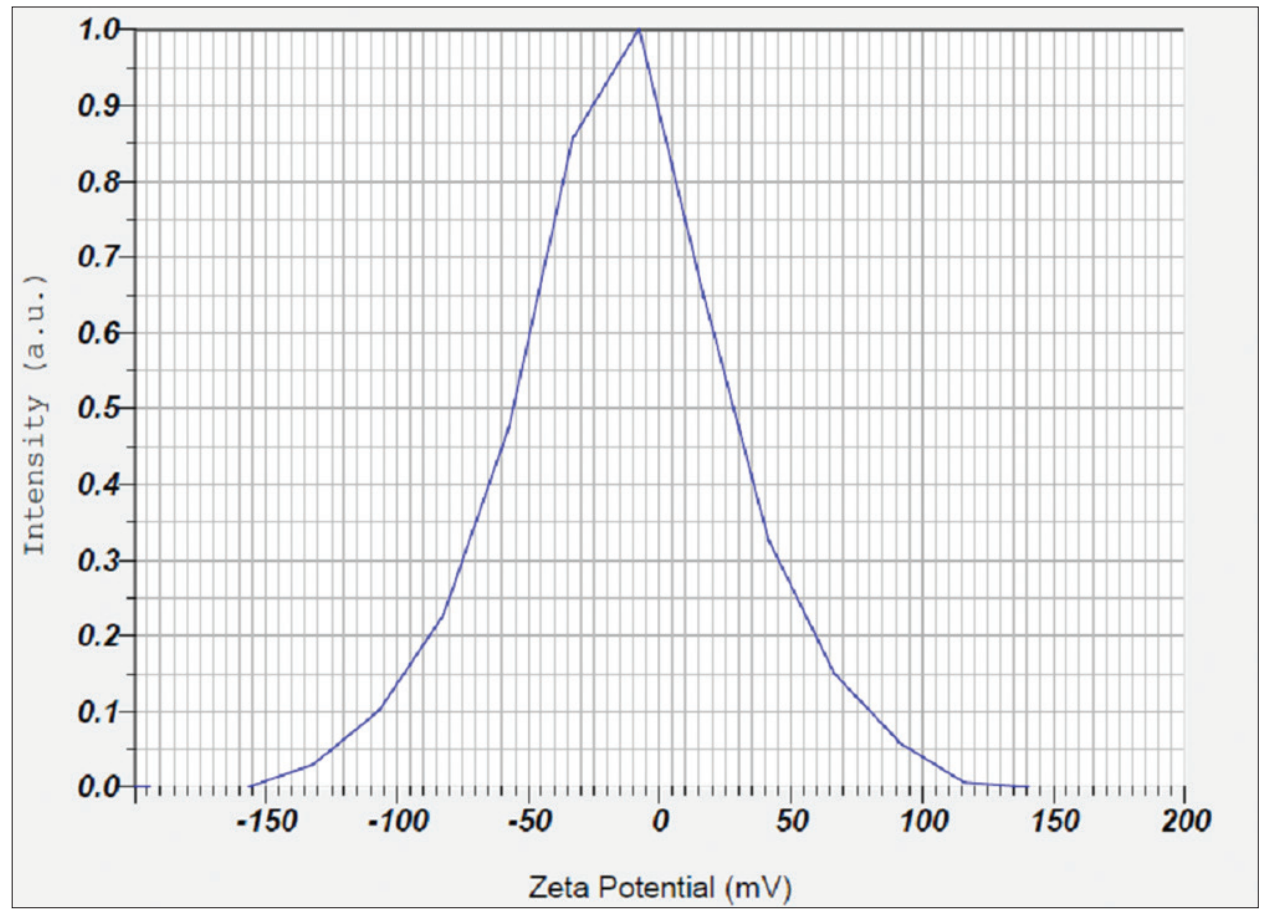

Fig. 5: Measurement of zeta potential (sample)

studies of all formulations are given in Table 6, and the statistically represented is shown in Fig. 6.

The percentage drug release of all formulations after $4.5 \mathrm{~h}$ using Carbopol was identified to be $96.12 \%$ (F1), 98.72\% (F2), 99.01\% (F3), and $99.34 \%$ (F4), respectively. The most essential factors in the drug release are the type of polymer by the concentration of polymer.

\section{Stability study}

There was no noticeable difference in the in vitro drug release study F1 (from $96.96 \%$ to $96.62 \%$ ) at $30 \pm 2^{\circ} \mathrm{C}$ at $65 \pm 5 \mathrm{RH}$. After storing at $40 \pm 2^{\circ} \mathrm{C}$ at $75 \pm 5 \mathrm{RH}$ the in vitro drug release study of $\mathrm{F} 1$ formulation is decreased. The statistics are stated in Table 7. This was discovered that the developed itraconazole gel formulae and its storage were identified to be firm for 2 months at room temperature; there were no changes in the specification that is inflated such as physical aspect as color, drug content, and drug release during the inspection.

Stability studies were carried for the most effective formulation-F1, at $30 \pm 2^{\circ} \mathrm{C}$ and $40 \pm 2^{\circ} \mathrm{C}$ at $65 \pm 5$ and $75 \pm 5 \mathrm{RH}$ for 2 months. At the end of 2 months, samples were evaluated. Drug content study showed that there was no major change in the content drug of F1 (from $98.01 \%$ to $98.39 \%$ ) at $30 \pm 2^{\circ} \mathrm{C}$ at $65 \pm 5 \mathrm{RH}$ and decrease at $40 \pm 2^{\circ} \mathrm{C}$ at $75 \pm 5 \mathrm{RH}$ (from $97.48 \%$ to $97.87 \%$ ). The data are presented in Table 8.

\section{DISCUSSION}

The triazole derivative of itraconazole is one of the best drugs suited for the treatment of fungal infections. In this study, the topical gel preparation of itraconazole was formulated for efficient 


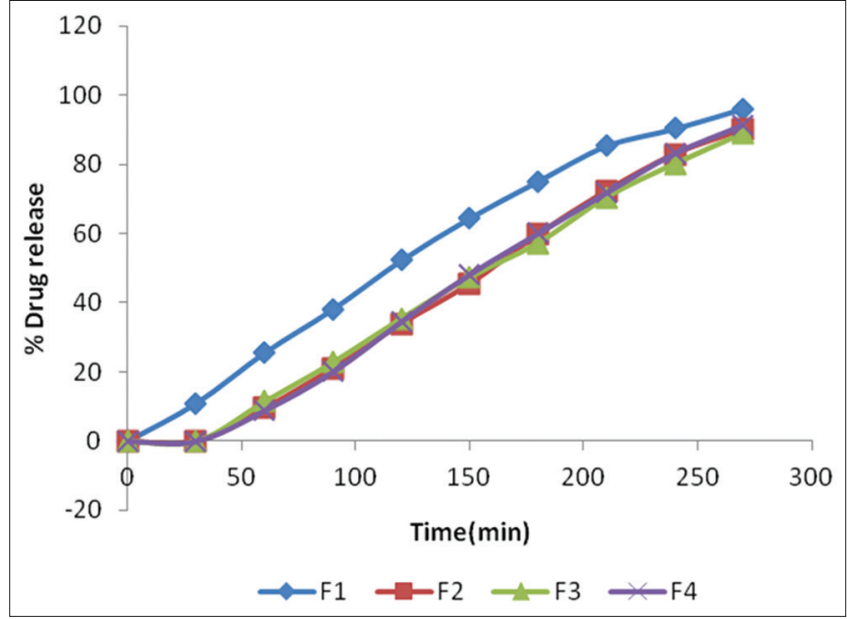

Fig. 6: Comparative dissolution study of different formulations with various ratios of polymers

that transports the drug across the skin. UV spectrophotometry surveys of prepared itraconazole gel manifest the absorption at the wavelength of $269 \mathrm{~nm}$. The utility of the associated coefficient was endowed to be $\mathrm{R}^{2}=0.9998$, that obeys beers law. The obtained FTIR peaks showed the drug-excipients compatibility. Different ratio of the formulation (F1, F2, F3, and F4) was advanced using suitable polymer (Carbopol 940p) and infiltration enhancer. Advanced formulations of itraconazole were analyzed for physiochemical parameters such as viscosity, spreadability, drug content, and in vitro drug release studies. From all the build out formulation, F1 manifest drug liberates for a phase of $4.5 \mathrm{~h}$. The most efficient formulation of F1 shows a significant change in drug contents. The formulated drug stability was monitored for 2 months at $30 \pm 2^{\circ} \mathrm{C}$ and $65 \pm 5 \mathrm{RH}$. It was found that the drug showed good stability at the opted appropriate condition.

\section{CONCLUSION}

By bearing the above result, we able to conclude that our drug itraconazole was incorporated with success into the topical gel construction among all the built formulation the formulation F1 manifest better spreadability, drug content, viscosity, and drug liberation studies. Therefore, this was ceased that our formulation would be very assuring topical alternative for the treatment of skin fungal infections.

\section{REFERENCES}

1. Rathod HJ, Mehta DP. A review on pharmaceutical gel. Acta Sci Int J Pharm Sci 2015;1:33-47.

2. Verma A, Singh S, Kaur R, Jain UK. Topical gels as drug delivery systems: A review. Int J Pharm Sci Rev Res 2013;23:374-82.

3. Smart JD, Mortazavi SA. Drug delivery research group. J Pharm Pharmacol 1994;46:86-90.

4. Bhalaria M, Naik S, Misra A. A novel delivery system for antifungal drugs in the treatment of topical fungal disease. Indian J Exp Biol 2009;47:368-75

5. Gupta GD, Gound RS. Release rate of nimesulide from different gallants. Indian J Pharm Sci 1999;61:229-34.

6. Sera UV, Ramana MV. In vitro skin absorption and drug release-a comparison of four commercial hydrophilic gel preparations for topical use. Indian Pharm 2003;73:356-60.

7. Sahoo SK, Samal AR. Estimation and evaluation of secnidazole. Indian Pharm 2006;5:73.

8. Basha BN, Prakasam K, Goli D. Formulation and evaluation of gel containing fluconazole-antifungal agent. Int $\mathrm{J}$ Drug Dev Res 2011;3:109-28.

9. Deveda P, Jain A, Vyas N, Khambete H, Jain S. Jellified emulsion for sustain delivery of itraconazole for topical fungal diseases. Int J Pharm Pharma Sci 2010;2:104-12.

10. Shah M, Modi D, Shah D. Formulation, design and evaluation of microemulsion and micro emulgel of itraconazole for topical application. Int J Pharm Pharm Res 2017;9:125-46.

11. Nirosha M, Varsh KH, Prema AR, Samdani K, Amrutha V, Reddy LD. Formulation and evaluation of itraconazole ophthalmic in situ gels. J Power Source 2017;4:1101-8.

12. Baudonnet L, Pere D, Michaud P, Grossiord JL, Rodriguez F. Effect of dispersion stirring speed on the particle size distribution and rheological properties of carbomer dispersions and gels. J Dispers Sci Tech 2002;23:499-510

13. Gupta A, Mishra AK, Singh AK, Gupta V, Bansal P. Formulation and evaluation of topical gel of diclofenac sodium using different polymers. Drug Invent Today 2010;5:250-3.

14. Skiba M, Skiba-Lahiani M, Marchais H, Duclos R, Arnaud P. Stability assessment of ketoconazole in aqueous formulations. Int $\mathrm{J}$ Pharm 2000;198:1-6.

15. Shivhare UD, Jain KB, Mathur VB, Bhusari KP, Roy AA. Formulation development and evaluation of diclofenac sodium gel using watersoluble polyacrylamide polymer. Dig J Nanomater Biostruct 2009;2:285-90.

16. Marjukka Suhonen T, Bouwstra JA, Urtti A. Chemical enhancement of percutaneous absorption in relation to stratum corneum structural alterations. J Control Release 1999;59:149-61.

17. Chudasama A, Patel V, Nivsarkar M, Vasu K, Shishoo C. Investigation of microemulsion system for transdermal delivery of itraconazole. J Adv Pharm Technol Res 2011;2:30-8. 